AperTO - Archivio Istituzionale Open Access dell'Università di Torino

\title{
When Therapists Cry: Implications for Supervision and Training
}

\section{This is the author's manuscript}

Original Citation:

Availability:

This version is available http://hdl.handle.net/2318/1543375

since 2016-06-23T16:19:23Z

Published version:

DOI:10.1080/07325223.2015.1048556

Terms of use:

Open Access

Anyone can freely access the full text of works made available as "Open Access". Works made available under a Creative Commons license can be used according to the terms and conditions of said license. Use of all other works requires consent of the right holder (author or publisher) if not exempted from copyright protection by the applicable law. 
This is the author's final version of the contribution published as:

Blume-Marcovici, Amy C; Stolberg, Ronald A.; Khademi, Mojgan; Giromini, Luciano. When Therapists Cry: Implications for Supervision and Training. The Clinical Supervisor. 34 (2) pp: 164-183.

DOI: $10.1080 / 07325223.2015 .1048556$

The publisher's version is available at:

http://www.tandfonline.com/doi/full/10.1080/07325223.2015.1048556

When citing, please refer to the published version.

Link to this full text:

http://hdl.handle.net/2318/1543375 
When therapists cry: Implications for supervision and training

Amy C Blume-Marcovici*, Ronald A Stolberg*, Mojgan Khademi*, Luciano Giromini** *Alliant International University **University of Turin, Italy

Special thanks to Dr. Matthew Porter for his invaluable insights and support of this project 


\begin{abstract}
The majority of psychologists cry in their role as therapists but no research has explored training or supervision in relation to this topic. Psychologists and trainees $(N=686)$ filled out a survey on therapist crying in therapy. Almost all (96.5\%) reported that psychologists should be trained on how to handle their emotions, but only $36.4 \%$ reported receiving training on therapist crying. Half of all respondents reported having discussed crying with a supervisor; one third had never discussed their most recent tears with anyone. Suggestions are offered for supervisors in order to manage discussion of TCIT in psychotherapists' training.
\end{abstract}

Keywords: therapist crying, tears, emotional expressions, supervision, training, consultation 
When Therapists Cry: Implications for Supervision and Training

Psychologists cry in therapy. In 1987, Pope, Tabachnick, and Keith-Spiegel published results of a survey on which $57 \%$ of their 456 psychotherapist respondents reported that they had cried in the presence of a client. More recently, Blume-Marcovici, Stolberg and Khademi (2013) reported that $72 \%$ of psychologists and psychology trainees had cried at least once during a therapy session with a client. Findings from these studies indicate that the majority of psychologists and psychology trainees will experience therapist crying in therapy (hereafter, TCIT) at some point in their career. Indeed, research reports that those therapists who cry in therapy cry in approximately $7 \%$ of therapy sessions (Blume-Marcovici et al., 2013). Compared to prior research that has found clients to cry in approximately $21 \%$ of therapy sessions (Trezza, Hastrup, \& Kim, 1988), these numbers allow us to estimate that therapists cry in therapy approximately one third as often as their clients, though this percentage does not account for intensity or duration of tears.

Researchers have found that therapists are most likely to cry when session content focuses on grief, trauma, and termination of therapy (Blume-Marcovici, Stolberg, \& Khademi, 2015), and that the most commonly reported emotions the therapist felt when crying in therapy are sadness, emotionally “touched," warmth, and loss (Blume-Marcovici et al., 2015). Although most of the time therapists reported that their tears were focused on the client, in $16 \%$ of cases therapists reported that their tears were related to their own (i.e., the therapist's) personal circumstance (Blume-Marcovici et al., 2015). And, although $82 \%$ of therapists reported that they believed TCIT helped the client feel that his/her therapist genuinely cared, 69\% expressed concern that TCIT would cause the client to feel that the therapist would not be able to handle the client's emotion (Blume-Marcovici et al., 2013). Despite the fact that the majority of 
therapists believe TCIT can impact the therapy - in both positive and negative ways - no research exists regarding training, supervision, or consultation on TCIT.

Given that the number of behaviors on which a supervisor could focus is infinite, one may wonder whether supervisory focus on TCIT specifically is warranted. For several reasons, we purport that it is. To begin, crying is part of the human attachment system: tears, in their function as an attachment behavior, are a means of eliciting support and help from others (Bowlby, 1969; Laan, Van Assen, \& Vingerhoets, 2012; Nelson, 2008). As such, TCIT can help provide information about the client's attachment style in conjunction with that of the therapist's. In a chapter on crying (by the client) in psychotherapy, Nelson explained that the the therapist's own internal responses to a crying client - which, she noted, may lead to TCIT - provided useful information about what their client is grieving, where their client is in the grieving process, as well as the client's attachment orientation. In this way, the therapists' reaction to the client's tears (particularly TCIT) could have important diagnostic and treatment-planning implications.

TCIT may also, at times, represent a sort of attachment role reversal in which the caregiver (therapist) is seeking care (Nelson, 2005). For example, therapists may weep at times due to a desire for nurturance or comfort (from their client). Although TCIT does not always indicate such a role reversal in treatment, therapists' tears may help pinpoint important shifts and dynamics between client and therapist, and highlight critical moments which could destabilize (should TCIT lead to a rupture in the alliance that goes unrepaired) and/or vitalize (should TCIT lead to a deepening in the alliance) therapy. Supervisees may need assistance in addressing such situations and sorting through the complex dynamics of the therapist's and client's attachment orientations that may lead to therapists' tears in the clinical encounter. 
Just as some writers have focused on the ways in which tears represent part of the human attachment system, others have argued that crying is intrinsically social in nature: humans cry to communicate something to others (Cornelius \& Labott, 2001; Kottler, 1996; Ruesch \& Rees, 1959). Although prior literature has been focused on how a therapist may work with his or her emotions in therapy in general (e.g., Kimerling, Zeiss \& Zeiss, 2000; Yalom, 2002), tears are not emotions themselves, but are social and interpersonal expressions of emotions, and their very presence (or lack thereof) is influenced by the presence of other people (Vingerhoets, Boelhouwer, Van Tilburg, \& Van Heck, 2001). In the case of TCIT, the other person is the client. In this way, TCIT by definition brings the therapist's emotions into the room and demands recognition on some level by the therapist, the client and, therefore, the two together, whether or not this recognition is explicit or covert. Although therapists may learn, in supervision and training, to work with and manage their own emotions, this may or may not include learning how to work with and manage such emotions as they become visible and alive within the therapy room.

Additionally, TCIT is the type of event which supervisees are less likely to disclose to their supervisors (Ladany, 2004). Ladany (2004) reported on typical supervisee non-disclosures, which included non-disclosure of countertransference reactions and clinical mistakes, as well as non-disclosure of positive supervisee reactions to their clients, particularly in terms of feeling close to the client. TCIT can represent each of these categories, with psychologists at times perceiving their TCIT to be a form of countertransference (Blume-Marcovici, 2012; Counselman, 1997; Owens, 2005; Waldman, 1995), at times worrying that their TCIT was a therapeutic blunder (Blume-Marcovici et al., 2015; Owens, 2005; Rhue, 2001; Waldman, 1995), and at other times feeling that their TCIT represented a moment of real connection and closeness 
with their client (Blume-Marcovici, 2012; Counselman, 1997; Owens, 2005; Waldman, 1995). In this way, TCIT may be a likely candidate for non-disclosure in the supervision process. Previous supervision researchers have found that when supervisees hide information from supervisors, the supervisory working alliance is perceived to be weaker (Ladany, Hill, Corbett, \& Nutt, 1996). Thus, facilitating disclosure and discussion of TCIT may enhance the supervisory alliance.

Finally, although no researchers have focused on supervision or training regarding TCIT in psychology, research has been conducted on crying amongst medical professionals. In a 2009 study of medical trainees, Sung et al. (2009) found that the vast majority of medical trainees felt that discussion of physicians' crying was inadequate, and, in a recent study on tears of physicians, Majhail and Warlick (2011) emphasized the importance of supervision and “debriefing” with colleagues with regards to professionals' tears. From these articles, we can see that medical professionals have begun to focus on the importance of discussing physicians' tears in the training process during supervision. However, no psychological literature or research has yet been focused on the role of supervision and training in TCIT, despite psychology being a profession which focuses more explicitly on emotions and emotional expressions than other healthcare professions.

Thus, the purpose of the present study was to determine whether psychologists and psychology trainees receive training, supervision, and/or consultation regarding TCIT; who is most likely to receive such training, supervision, and/or consultation; and how prepared psychologists feel in managing TCIT. Specifically, our study attempted to answer the following questions:

1) Do psychologists receive trainings that include explicit focus on TCIT?

2) Do psychologists discuss TCIT with a supervisor? 
3) Do psychologists feel prepared to handle TCIT?

4) Does receiving training on TCIT correlate with feeling prepared to deal with TCIT? Because researchers have previously found differences in the rates of TCIT based on clinician's level of experience and theoretical orientation (Blume-Marcovici, et al., 2013), and because of the documented differences in rates of crying between males and females in general (Bylsma, Vingerhoets, \& Rottenberg, 2008; Vingerhoets, Cornelius, Van Heck, \& Becht, 2000) despite similar rates of TCIT (Blume-Marcovici, et al., 2013), and since the expression of emotion is moderated by culturally determined display rules (Ekman, 1973; Matsumoto, 1989) and freedom of expression in a given culture (van Hemert, van de Vijver, \& Vingerhoets, 2011), we also aimed to investigate whether any demographic or clinical experience variables were related to different experiences of training, supervision and consultation with respect to TCIT.

\section{Method}

\section{Research Design and Procedures}

We sought to investigate participants' experiences with training, supervision, and consultation in relation to TCIT. All data were collected through a single, cross-sectional, retrospective, self-report internet survey. The study and survey instruments were approved through Alliant International University's Institutional Review Board. A recruitment email, with a hyperlink to the survey, was sent to university program directors of both counseling and clinical psychology doctoral programs, psychology training sites (all APPIC and CAPIC sites), and psychology associations throughout the United States. Participants were asked to give their consent to participating by checking "yes" or "no" on a consent form. Of note, we defined crying following the Adult Crying Inventory (Vingerhoets \& Cornelius, 2001): "tears in one's eyes due to emotional reasons" (p. 1). 


\section{Participants}

As part of a larger research project (Blume-Marcovici, 2012), 684 US psychologists, postdoctoral psychology fellows, and psychology graduate students filled out a survey on TCIT. Of these, 541 (79\%) participants completed the survey in full. In order to increase power and represent all of the individuals who participated in the study, even in part, data are included when available for each question. In this regard, it should be noted that percentage of missingness across the items included in the current study ranged from $0.0 \%$ (i.e., 0 out of 8 items) to $62.5 \%$ (i.e., 5 out of 8 items) and that missingness across those items occurred randomly, as demonstrated by a nonsignificant chi-square test (missingness by item), $\chi^{2}(7)=9.3, p=.23$. Crucially, we also tested whether including in the analyses only the participants who completed the survey in full versus including all available participants for any given questions would produce different results. These additional analyses revealed that either approach would in fact lead to the same conclusions (the biggest difference between the two approaches consisted of a variation of $0.7 \%$ in the percentage of response of one category of one of the variables). This result is consistent with a recent Monte Carlo, simulation study indicating that when data are missing at random, listwise and subpopulation analyses tend to produce similar results (Bell, Kromrey, \& Ferron, 2009).

In terms of sex, $75 \%(n=515)$ of survey respondents were female, $25 \%(n=169)$ male $(N=684)$. Ethnically, $80 \%(n=523)$ of respondents identified as non-Hispanic White, $5 \%(n=$ 36) as Asian or Asian American, 5\% $(n=31)$ as Hispanic or Latino, and 3\% $(n=18)$ as Black or African American. Other ethnicities made up 7\% $(n=42)$ of respondents. The mean age of respondents was 36 years $(S D=11.2$, range $22-85$ years $)(N=640)$. At least 40 US states were represented $(N=551)$. In terms of professional status, $57 \%(n=390)$ of respondents were 
graduate students in doctoral programs in psychology, 40\% $(n=273)$ were licensed psychologists, and 3\% ( $n=21)$ were post-doctoral fellows $(N=684)$. Of the licensed psychologists, the mean number of years licensed was 9.6, ( $S D=8.9$, range 1-33 years). Regarding theoretical orientation, 36\% $(n=242)$ of respondents identified as having a psychodynamic emphasis, 35\% $(n=232)$ identified as cognitive-behavioral therapists $(\mathrm{CBT})$, $19 \%(n=129)$ as eclectic/integrative without a psychodynamic emphasis, and 10\% $(n=68)$ as "other" $(N=671)$.

\section{Measures}

As part of a larger research project (Blume-Marcovici, 2012), participants completed two surveys: TCIT Survey 1, a 40-item survey evaluating who cried in therapy which was administered to all survey respondents and TCIT Survey 2, a 49-item survey which was administered only to those respondents who reported having previously cried in therapy, and included both quantitative and qualitative sections evaluating past experiences of TCIT. The surveys were developed by the research team in order to gather preliminary information about a topic that had never before been investigated in survey format. The TCIT Surveys 1 and 2 were piloted on a group of 20 psychology graduate students.

In the present study, we analyzed survey items on both TCIT Surveys 1 and 2 that were closely related to participants' training and supervision experiences. Eight items that directly addressed one the four major research questions were analyzed, all of which were measured on a 7-point Likert scale, with response categories ranging from Strongly Disagree to Strongly Agree (for details, see Table 1).

\section{Data Analysis}


The major goal of this study was to survey opinions, biographical data, and attitudes of psychologists and trainees with respect to TCIT. Thus, we mainly examined the percentage of respondents showing agreement or disagreement with each of the selected statements. In discussing descriptive statistics from these items, ratings corresponding to Strongly Disagree, Disagree, and Somewhat Disagree responses were aggregated into a "Disagree" score, while scores corresponding to Strongly Agree, Agree, and Somewhat Agree responses were aggregated into an "Agree" score, in order to give the raw data interpretive meaning.

We also conducted additional analyses aimed at testing whether any demographic or background variables accounted for the different attitudes/opinions reported by our respondents. For this purpose, a series of $t$-tests examined the differences of gender, ethnicity, level of clinical experience, theoretical orientation, and therapeutic stance of the respondents on all eight items selected for the current study. Though the $t$-test is fairly robust in respect to violations of assumptions, in order to account for potential nonnormality and other distributional issues, we also conducted a series of Mann-Withney tests (i.e., the non-parametric analogous of the $t$-test). The results of these additional analyses led to the same conclusions of the $t$-tests.

\section{Results}

\section{Do psychologists receive trainings that include explicit focus on TCIT?}

Slightly more than half $(55.5 \%)$ of respondents disagreed to some extent with the statement, "During my training, attention was paid to how I should handle crying in therapy," suggesting that more than half did not feel that during their training attention was paid to how they should handle TCIT (see Table 1). Approximately one-third (36.4\%) indicated that they did receive some training on how to handle TCIT. Noteworthy, less than $1 \%$ somewhat disagreed 
with the statement, "Psychologists should be trained in how to handle their own emotions during therapy," while the great majority (96.5\%) reported they did agree, at least to some extent.

\section{Do psychologists discuss TCIT with a supervisor?}

Another important aspect related to TCIT is whether, after TCIT, psychologists tend to discuss it, or not, with their supervisors. In our sample, 50.2\% somewhat agreed with the following statement: "I have discussed how to handle my own tears in therapy with a supervisor or colleague." To explore whether the respondents who discussed TCIT with a supervisor are the same ones who received training on it, we computed a 2 by 2 contingency table. As reported in Table 2, psychologists who were trained on how to handle TCIT tended to discuss it with a supervisor more often than those who did not, $P h i=.53, p<.001$.

We next focused our analyses on those respondents who did cry in psychotherapy $(n=$ 411), and examined whether (a) they sought supervision after their most recent experience of crying in therapy ("I sought supervision after my most recent experience of crying in therapy"), and (b) if they talked about it with someone after TCIT occurred ("I have never told anyone about my most recent experience of crying in therapy"). Although just about one third (33.8\%) of these respondents reported that they had sought supervision or consultation after their most recent TCIT episode, approximately two thirds (68.7\%) reported that they had talked with someone (not necessarily a supervisor) about their TCIT experience. In written-in responses, respondents reported that this "someone" could be a peer trainee, personal therapist, or significant other. On the other hand, about one quarter (26.9\%) of the respondents who experienced TCIT reported that they had not spoken with anyone about their experience with TCIT after having cried.

\section{Do psychologists feel prepared to handle TCIT?}


For those psychologists who have cried during therapy with a client, a little more than half $(58.3 \%)$ felt prepared for how to handle their crying in their most recent experience of TCIT (“I was prepared for how to handle crying in therapy"). Over a quarter of respondents (27.9\%), did not feel prepared for how to handle their tears.

Interestingly, the less prepared a therapist reported feeling when he or she cried in therapy, the more the respondent reported regretting their tears ("I wish I had not cried in therapy"; $r=-.34, p<.001$ ) and to believe their TCIT had been a mistake ("My tears in therapy were a mistake"; $r=-.31, p<.001)$. Furthermore, therapists who regretted crying in therapy also tended to report that they had never told anyone about their TCIT episode ("I wish I had not cried": $r=.21, p<.001 ;$ "My tears were a mistake": $r=19, p<.001)$.

\section{Does receiving training(s) on TCIT correlate with feeling prepared to deal with TCIT?}

There was a significant positive correlation between feeling prepared to handle TCIT ("'I was prepared for how to handle crying in therapy") and agreement with the statement, "During my training, attention was paid to how I should handle crying in therapy" $(r=.34, p<.001)$, with those respondents whose training incorporated how to handle TCIT reporting feeling more prepared when TCIT did occur. Indeed, having received training on how to handle TCIT correlated more strongly with feeling prepared to handle TCIT than did level of experience as a clinician, as found in a partial correlation. Specifically, when controlling for level of experience, having received training on how to handle TCIT correlated more strongly with feeling prepared for how to handle TCIT $(r=.42 ; p<.001)$ than did level of experience and feeling prepared, when controlling for having received training $(r=.24, p<.001)$.

\section{Additional Analyses}


Additional analyses aimed at investigating whether any demographic or background variables may account for the attitudes of the surveyed psychologists with respect to training and TCIT. Specifically, we focused on the role of gender, ethnicity, level of clinical experience, theoretical orientation, and therapeutic stance of the respondent. All eight items reported in Table 1 were examined as dependent variables in these additional analyses. Thus, a Bonferronicorrected alpha value of 0.00625 (i.e., 0.05 divided by 8 ) was used to control for inflation in family-wise error.

Sex. Significant sex differences were found regarding training and supervision experiences, with men reporting fewer experiences of training and supervision on TCIT and being less likely to discuss their TCIT with a supervisor or colleague than women. Specifically, men were significantly more likely than females to disagree with the statements "During my training, attention was paid to how I should handle crying in therapy", $t(575)=3.00, \mathrm{p}=.003, d$ $=.30$ (males: $n=136, M=3.02, S D=1.86$; females: $n=441, M=3.56, S D=1.82$ ), "I have discussed how to handle my tears with a supervisor", $t(582)=5.81, \mathrm{p}<.001, d=.57$ (males: $n=$ 137, $M=3.07, S D=2.08$; females: $n=447, M=4.26, S D=2.11$ ) and "I sought supervision after my most recent TCIT episode", $t(359)=2.84, p=.005, d=.37$ (males: $n=75, M=2.75$, $S D=2.11$; females: $n=286, M=3.51, S D=2.06$ ).

Ethnicity. The study sample identified largely (80\%) as non-Hispanic White, with only small numbers of respondents from other ethnic groups. Thus, to test whether ethnicity may account for the different attitudes of the surveyed psychologists with respect to training and TCIT, we compared our non-Hispanic White respondents against all other respondents. Results failed to show any statistically significant differences. The most notable difference was that nonHispanic White individuals tended to disagree more than other respondents with the statement " $I$ 
sought supervision after my most recent TCIT episode", $t(355)=2.18, p=.030, d=.30$ (nonHispanic White: $n=293, M=3.23, S D=2.08$; Others: $n=64, M=3.86, S D=2.12$ ). However, this result also was not statistically significant. All in all, thus, one may conclude that ethnicity had a small impact, if any, on the results of our survey.

Level of clinical experience. When compared to graduate students and post-doctoral trainees, licensed psychologists tended to agree more with the statement, "I was prepared for how to handle crying in therapy", $t(360)=3.54, p<.001, d=.37$ (licensed psychologists: $n=$ 170, $M=4.82, S D=1.68$; trainees: $n=192, M=4.22, S D=1.60$ ). They tended to agree less with the statement, "I sought supervision after my most recent TCIT episode", $t(359)=6.17, p<$ $.001, d=.65$ (licensed psychologists: $n=169, M=2.66, S D=1.87$; trainees: $n=192, M=3.96$, $S D=2.09)$.

Theoretical orientation and therapeutic stance. Dynamically-oriented therapists tended to report more experiences with training and supervision on TCIT than did CBT therapists (comparing these two groups specifically). In fact, dynamic therapists were significantly more likely than CBT therapists to agree with the statement, "I have discussed TCIT with a supervisor", $t(409)=3.94, p<.001, d=.39$ (psychodynamic: $n=207 ; M=4.34, S D=$ 2.22; CBT: $n=204 ; M=3.51, S D=2.06$ ). Albeit nonsignificant from a statistical standpoint, another interesting result was that dynamic therapists seemed more likely to agree with the statement, "During my training, attention was paid to how I should handle crying in therapy", $t(403)=2.35, p=.019, d=.24$ (psychodynamic: $\mathrm{n}=203 ; \mathrm{M}=3.57, \mathrm{SD}=1.88 ; \mathrm{CBT}: \mathrm{n}=202 ;$ $\mathrm{M}=3.13, \mathrm{SD}=1.83$ ). Along the same lines, another interesting - but not statistically significant - result was that dynamically-oriented therapists seemed to agree more than CBT therapists with the statement, "Psychologists should be trained in how to handle their own emotions during 
therapy", $t(403)=2.46, p=.014, d=.24$ (psychodynamic: $n=203 ; M=6.41, S D=0.82$; CBT: $n=202 ; M=6.21, S D=0.86)$.

CBT therapists tended to regret more than dynamic therapists their tears in therapy sessions. Indeed, compared to dynamically-oriented therapists, CBT therapists tended to agree more with the statement, "My tears in therapy were a mistake", $t(315)=2.98, p=.003, d=.34$ (psychodynamic: $n=139 ; M=1.87, S D=1.01 ; \mathrm{CBT}: n=178 ; M=2.29, S D=1.38$ ).

\section{Discussion}

\section{Training, Supervision, and Consultation on TCIT}

Respondents in the present study largely (96.5\%) reported that psychologists should be trained to handle their emotions but generally reported that their own training did not include how to handle TCIT (55.5\%). Although half of respondents had discussed TCIT with a supervisor or colleague at some point, only about one third (33.8\%) had discussed their most recent experience of TCIT with a supervisor, and just over a quarter (26.9\%) had never told anyone about their more recent experience of crying in therapy. From this study, it appears that psychologists and psychology trainees who are female, who have fewer years of clinical experience, and who are psychodynamically-oriented (versus CBT therapists) are more likely to have received or to seek training, supervision, and/or consultation on TCIT.

Regarding sex of respondent, the women were more likely to receive supervision than the men despite equal rates of crying in therapy amongst men and women (Blume-Marcovici et al., 2013). In other words, male therapists are just as likely to experience TCIT as females, but they are less likely to disclose or discuss it with a supervisor or colleague. It may be that male therapists are less likely to discuss TCIT with supervisors due to feelings of shame or concern that they are breaking perceived gender norms regarding emotional expression (Levant, 2001). 
Researchers have shown that males tend to have more negative views of their own sex's tears than of female's tears (Lombardo, Cretser, Lombardo, \& Mathis, 1983), suggesting that male trainees may have a harsher view of their own TCIT than female trainees do of theirs, or perhaps male supervisors have more negative reaction to male trainees tears, making male trainees particularly unlikely to disclose TCIT if they are paired up with a male supervisor. It also may be that supervisors in general are less likely to inquire about their male trainees' emotional expressions, or TCIT specifically, because supervisors do not expect such emotional expressivity from their male trainees. The term normative male alexithymia (Levant, 2001) has been used to capture males' tendency to be less emotionally expressive, which Levant argued is influenced by the social expectation that males are less emotional than females. In this way, cultural stereotypes and biases influence the supervision process: men may be less likely to discuss TCIT - or supervisors may be less likely to inquire about TCIT with male supervisees - due to a cultural belief that men should not cry.

Regarding years of clinical experience, it is perhaps not surprising that those with fewer years of experience reported receiving supervision on TCIT after their most recent episode of crying in therapy significantly more frequently than those with more experience, given that those in training have supervisors with whom they regularly meet for supervision. Thus, trainees' accessibility to consultation is higher than for a private practice clinician, for instance, who would have to seek out and likely pay for such a service. Additionally, training now may be more likely to focus on experiences such as TCIT, as the frame of therapy and ideas about neutrality in therapy have shifted over time (Agatsuma, 2014; Aron, 1996; Bernstein, 1999). Thus, licensed psychologists with more years of experience may be less likely to seek consultation on TCIT due to having been trained in a tradition that upheld neutrality more 
strictly. An alternative explanation is that those with more years of experience have learned over time that TCIT is relatively normative, and that they do not feel the need to seek consultation or peer support around the issue. It is note-worthy - and perhaps intuitive - that those with fewer years of experience are less likely to feel prepared to handle their tears, more likely to feel that their tears were a mistake, and more likely to keep their tears a secret (cf. Ladany, 2004).

Regarding theoretical orientation specifically, some writers have reported that psychodynamic clinicians focus more on emotional expression than other orientations (Blagys \& Hilsenroth, 2000) and such focus on affect likely carries over into the supervision process. Thus, while speculative, it is possible that psychodynamic supervisors may be more likely to ask about TCIT than supervisors from other theoretical orientations. It has also been noted that a psychodynamic approach to supervision encourages paying attention to countertransference (Lane, Barber, \& Gregson, 1998) more so than supervision in cognitive-behavioral therapy specifically. In turn, when psychodynamic supervisees experience their TCIT as a countertransference reaction (Blume-Marcovici, 2012), they may be more likely to discuss their TCIT with their supervisor, thus leading to higher reports of supervision on TCIT by psychodynamic therapists. Interestingly, both of the survey items regarding supervision and training on which respondents differed significantly in their responses based on theoretical orientation ("I have discussed TCIT with a supervisor" and "During my training, attention was paid to how I should handle crying in therapy") were survey items administered to all survey participants, whether or not they had cried in therapy (i.e., TCIT Survey 1). Those questions regarding supervision and training asked only of respondents who had cried in therapy (i.e., TCIT Survey 2) found no significant differences between dynamically-oriented and CBT therapists. Thus, it appears that dynamic and CBT clinicians differ in their views of their training 
and supervision experiences, especially when the views of those respondents who reported never having cried in therapy are incorporated. We may surmise that dynamically-oriented trainers or supervisors may be more likely to address the possibility of TCIT pre-emptively - whether or not their trainee/supervisee has cried - than CBT clinicians. Once TCIT occurs, it appears that respondents are equally likely (or unlikely, as it may be) to seek supervision, regardless of theoretical orientation.

We also found that individuals who reported having received training on how to handle their tears in therapy or who reported having discussed their tears with a supervisor or consultant also tended to report feeling prepared for how to handle their tears in therapy. Individuals who had not received training or supervision tended to report regret about TCIT. In this way, receiving training and/or supervision on TCIT may influence a clinicians' sense of competence and comfort in the room, as well as allow clinicians to feel more prepared when TCIT does occur. In fact, receiving training was a greater factor in feeling competent in dealing with TCIT than was the amount of experience a clinician had in clinical practice. From these findings it appears that supervision and training with regards to handling the therapist's own emotions in session may have great benefit.

Similar to a study of medical professionals, in which trainees reported inadequate discussion of physician crying (Sung et al., 2009), we found that over a quarter (26.9\%) of respondents had never discussed their most recent TCIT experience with anyone and only $8 \%$ of respondents strongly agreed that they were "prepared for how to handle TCIT." It is notable that, while only one third of respondents sought supervision after their most recent TCIT episode, two thirds of respondents reported speaking with "someone," including peers, personal therapists and significant others. In other words, one third of respondents who did not discuss their TCIT in 
supervision or consultation felt the experience to be noteworthy enough to speak about with someone else in their life. Unfortunately, we did not collect information about why these individuals chose not to discuss their TCIT in supervision in the present study. Overall, findings from the present study and implications from related medical research suggest that discussion of TCIT in supervision and consultation should be more commonplace. Proactive training on TCIT may make a supervisee less likely to hide TCIT in supervision when it does occur (as participants from the present study who received training or supervision on TCIT were less likely to report never having discussed their tears). As discussed previously, the supervisory working alliance is perceived to be stronger when the supervisee feels comfortable and able to disclose difficult topics (and weaker when such topics are kept secret; Ladany, Hill, Corbett, \& Nutt, 1996), such as TCIT.

\section{Suggestions for training directors, supervisors and consultants}

In order to facilitate discussion of TCIT in training, supervision, and consultation, several suggestions are offered here.

Normalize. The majority of psychologists have cried in therapy with a client, with estimates ranging from 57\% (Pope et al., 1987) to 72\% (Blume-Marcovici et al., 2013). If a trainee, supervisee, or colleague consults regarding his or her own TCIT, normalization of TCIT by the trainer or supervisor may be helpful to reduce potential feelings of discomfort, shame, or regret (Hahn, 2001). Indeed, preemptive normalization in the form of anticipating TCIT with supervisees is encouraged. Supervisors should discuss the possibility of TCIT with new supervisees and let them know that it would be an appropriate topic to bring up during training or after TCIT with a client. Trainings or group supervision on TCIT may allow for open discussion of trainee emotionality and lead to particularly rich clinical discussion. 
Supervisor self-disclosure of TCIT. Researchers have shown that supervisor selfdisclosure regarding their own experiences as a therapist leads to a stronger supervisory working alliance (Knox et al., 2008; Knox et al., 2011; Ladany \& Lehrman-Waterman, 1999). Furthermore, a supervisor's disclosure of his or her own struggles as a therapist (which might include experiences with TCIT) positively impacts the emotional bond between the supervisor and trainee. In addition, supervisors who disclose intimate therapy experiences (which might include experiences with TCIT) with their supervisees strengthen the supervisory alliance by doing so, as well increase the level of supervisee disclosure (Ladany \& Lehrman-Waterman, 1999). Thus, if relevant, the supervisor should consider whether sharing his or her own experience(s) with TCIT could be helpful for the supervisee and, specifically, whether such sharing could strengthen the supervisory working alliance and increase the likelihood of supervisee disclosure.

Men cry, too. Supervisors should keep in mind that, based on research results (BlumeMarcovici et al., 2013), male therapists are significantly less likely to seek supervision regarding TCIT, despite equal rates of crying in therapy. It may be particularly incumbent upon the supervisor to ask about, normalize, and elicit discussion of TCIT with male supervisees. Supervisors should also note that TCIT occurred amongst all ethnic groups in the present sample. Supervisors should ask themselves whether any biases or cultural stereotypes regarding emotional expression might keep a supervisee from bringing up TCIT or keep the supervisor from asking about or discussing TCIT with a supervisee.

Hot topics. As reported in Blume-Marcovici et al. (2015), certain session topics are more likely to be accompanied by TCIT, including grief, trauma, and termination. Forced termination was the highest subset of TCIT-due-to-termination session content. As trainees generally 
experience multiple instances of forced termination sessions (i.e., terminations with clients due to trainee leaving a placement versus the "natural" ending of therapy), supervisor-initiated discussion of TCIT may be particularly useful in anticipation of and during these unnatural endings.

Mixed emotions. As described previously, the most common emotion for therapists to feel when they cry is sadness (Blume-Marcovici, et al., 2013). However, the next two most common emotions are feeling "emotionally touched" and feeling "warmth." Thus, it appears that the emotional valence of moments in which TCIT occurs is quite mixed (Blume-Marcovici et al., 2013). It is important for trainers, supervisors, and consultants to be aware that tears with clients may be accompanied by both "negative" and "positive" emotions for the therapist, and often a mixture of the two. Ladany (2004) pointed out that two common areas of supervisee nondisclosure are negative and positive reactions to clients. Thus, helping supervisees sort through their own range of emotions when TCIT occurs may be useful in understanding the unique interpersonal exchange that takes place between therapist and client when the therapist cries, as well as, again, decreasing supervisee non-disclosure in supervision.

Discussion of TCIT with the client. When working with TCIT in a training or supervisory role, it is important to ask about - or anticipate - therapist discussion of TCIT with the client. As reported elsewhere, discussion of TCIT with the client appears to correlate with improvement in rapport when TCIT occurs (Blume-Marcovici et al., 2015). Helping the trainee to think through the advantages and disadvantages of discussing TCIT with a client may be useful, and may provide opportunity for conceptualization of the client and understanding of the relationship dynamics (see Blume-Marcovici et al., 2015). For some trainees, role-playing how to discuss TCIT may be a productive way to work with potentially difficult moments in therapy 
(Frick-Helms, 2008), particularly if the trainee feels ashamed, uncomfortable, caught off guard, or worried about the implications of their TCIT for their client, or does not know how to manage - and make therapeutically productive - such moments in the clinical encounter. Indeed, permission from the supervisor to discuss these often un-discussed topics in supervision may allow the trainee to develop a model for discussing TCIT in therapy with their own clients.

Parallel process. It is worth wondering about the potential for parallel process between therapy and supervision (Searles, 1955) when it comes to TCIT. We might surmise, for instance, that just as therapists cry in therapy, supervisors also, at times, shed tears in supervision. Ladany, Walker, and Melincoff (2001) explained that supervisors who share their in-the-moment reactions to their supervisee with the supervisee convey investment in the supervision process by doing so. Thus, discussion of supervisor emotionality during supervision not only might provide an opportunity for the supervisory dyad to be strengthened, but also for the pair to discover parallels between the supervision and therapy process. Might the supervisor's tears, for instance, reflect emotions felt by the therapist/trainee and/or client? Discussion of the supervisors' emotionality could create opportunities for such metacommunication about the supervisory relationship that could enhance supervisee communication with their own clients (Tracey, Bludworth, \& Glidden-Tracey, 2011).

\section{Limitations}

A primary limitation of the present study is that data analysis involved statistical testing of single Likert scale questions. As this was a preliminary investigation into the topic of supervision and TCIT, future researchers could address more in-depth questions about the content, usefulness, and experiences of supervision regarding TCIT. A second limitation was that the perspectives of supervisors, trainers, and consultants were not included. Future researchers 
would do well to explore the perceptions of supervisors, trainers and consultants regarding their prior experiences in addressing TCIT, as well as their ideas about how to effectively do so.. In addition, the present study suffered from small numbers of participants from various ethnic groups. Efforts to maximize representation of therapists from diverse backgrounds should be made in future research. Also related to generalizability, Internet-based studies do not allow for an in-depth understanding of the participant base. For this reason, the generalizability of the study is challenged by the fact that we do not truly know whether participants who agreed to participate present different characteristics compared with those who did not participate. Finally, the study was based on self-report, which leaves the possibility of poor or incorrect recall. 


\section{References}

Agatsuma, S. (2014). Differentiating two kinds of neutrality. International Forum of Psychoanalysis, 23, 238-245.

Aron, L. (1996). A meeting of minds: Mutuality in psychoanalysis. Hillsdale, NJ: Analytic Press.

Bell, B. A., Kromrey, J. D., \& Ferron, J. M. (2009). Missing data and complex samples: the impact of listwise deletion vs. subpopulation analysis on statistical bias and hypothesis test results when data are MCAR and MAR. Proceedings of the Joint Statistical Meetings, Survey Research Methods Section, 26, 4759-4770.Bernstein, J. W. (1999). The politics of self-disclosure. Psychoanalytic Review, 86, 595- 605.

Blume-Marcovici, A. (2012). Tracking our tears: An empirical investigation of therapist crying in therapy. (Doctoral dissertation). Available from Dissertation and Theses database. (UMI No. 3503469)

Blume-Marcovici, A.C., Stolberg, R.A., \& Khademi, M. (2013). Do therapists cry in therapy?: The role of experience and other factors in therapists' tears. Psychotherapy: Theory, Research, Practice, Training, 50(2), 224-234. doi:10.1037/a0031384

Blume-Marcovici, A.C., Stolberg, R.A., \& Khademi, M. (in press). Examining our tears: Therapists' accounts of crying in therapy. American Journal of Psychotherapy. In press.

Blagys, M. D., \& Hilsenroth, M. J. (2000). Distinctive features of short-term psychodynamicinterpersonal psychotherapy: A review of the comparative psychotherapy processliterature. Clinical Psychology: Science and Practice, 7, 167-188. dio:10.1093/dinsy/7.2.167

Bowlby, J. (1969). Attachment. New York: Basic Books.

Bylsma, L. M., Vingerhoets, A. J., \& Rottenberg, J. (2008). When is crying cathartic? An 
international study. Journal of Social and Clinical Psychology, 27, 1165-1187. doi:10.1521/jscp.2008.27/10/1165

Cornelius, R. R., \& Labott, S. M. (2001). The social psychological aspects of crying. In A. J. J. M. Vingerhoets \& R. R. Cornelius (Eds.), Adult crying: A biopsychosocial approach (pp. 159-176). Hove, UK: Brunner-Routledge.

Counselman, E. F. (1997). Self-disclosure, tears, and the dying client. Psychotherapy, 34, 233-237. doi:10.1037/h0087715

Ekman, P. (1973). Cross-cultural studies of facial expression. In P. Ekman (Ed.), Darwin and facial expression (pp. 169-222). New York, NY: Academic Press.

Frick-Helms, S. B. (2008). Enhancing role play activities in play therapy supervision groups. In A. A. Drewes \& J. Mullen (Eds.)., Supervision can be playful: Techniques for child and play therapist supervisors (pp. 173-188), Lanham, MD: Jason Aronson.

Hahn, W. K. (2001). The experience of shame in psychotherapy supervision. Psychotherapy, 38, 272-282. doi: 10.1037/0033-3204.38.3.272

Kimerling, R. E., Zeiss, A. M., \& Zeiss, R. A. (2000). Therapist emotional responses to patients: Building a learning-based language. Cognitive and Behavioral Practice, 7, 312-321.

Knox, S., Burkard, A.W., Edwards, L.M., Smith, J. J., \& Schlosser, L. Z. (2008). Supervisors' reports of the effects of supervisor self-disclosure on supervisees. Psychotherapy Research, 18(5), 543-559. doi:10.1080/10503300801982781

Knox, S., Edwards, L. M., Hess, S. A., \& Hill, C. E. (2011). Supervisor self-disclosure: Supervisees' experiences and perspectives. Psychotherapy, 48(4), 336-341. doi:10.1037/a0022067

Kottler, J. A. (1996). The language of tears. San Francisco: Jossey-Bass. 
Laan, A. J., Van Assen, M. A. L. M., \& Vingerhoets, A. J. J. M (2012). Individual differences in adult crying: The role of attachment styles. Social Behavior and Personality, 40, 453472.

Ladany, N. (2004). Psychotherapy supervision: What lies beneath. Psychotherapy Research, 14, 1-19. doi:10.1093/ptr/kph001

Ladany, N., Hill, C. E., Corbett, M., \& Nutt, L. (1996). Nature, extent, and importance of what therapy trainees do not disclose to their supervisors. Journal of Counseling Psychology, 43, 10-24. doi: 10.1037/0022-0167.43.1.10

Ladany, N., \& Lehrman-Waterman, D. E. (1999). The content and frequency of supervisor selfdisclosures and their relationship to supervisor style and the supervisory working alliance. Counselor Education and Supervision, 38, 143-160. doi:10.1002/j.15566978.1999.tb00567.x.

Ladany, N., Walker, J. A., \& Melincoff, D.S. (2001). Supervisory style: Its relation to the supervisory working alliance and supervisor self-disclosure. Counselor Education and Supervision, 40, 263-275. doi:10.1002/j.1556-6978.2001.tb01259.x

Lane, R. C., Barber, S. S., \& Gregson, K. J. (1998). Divergent views in psychodynamic supervision. Journal of Contemporary Psychotherapy, 28, 187-197. doi:10.1023/A:1022915432268

Levant, R. F. (2001). Desperately seeking language: Understanding, assessing, and treating normative male alexithymia. In G. R. Brooks \& G. E. Good (Eds.), The new handbook of psychotherapy and counseling with men: A comprehensive guide to settings, problems, and treatment approaches, Vols. $1 \& 2$ (pp. 424-443). San Francisco: Jossey-Bass.

Lombardo, W. K., Cretser, G. A., Lombardo, B., \& Mathis, S. (1983). Fer cryin’ out loud - 
There is a sex difference. Sex Roles: A Journal of Research, 9, 987-995.

Matsumoto, D. (1989). Cultural influences of the perception of emotion. Journal of Cross-Cultural Psychology, 20, 92-105.

Majhail, N. S., \& Warlick, E. D. (2011). To cry or not to cry: Physicians and emotions at the bedside. Minnesota Medicine, 94(1). Retrieved from http://www.ncbi.nlm.nih.gov/pubmed/21366107

Nelson, J.K. (2005). Seeing through tears: Crying and attachment. New York: Routledge. Nelson, J. K. (2008). Crying in psychotherapy: Its meaning, assessment, and management based on attachment theory. In: A. J. J. M. Vingerhoets, I. Nyklicek, \& J. Denollet (Eds.), Emotion regulation and health. Conceptual and clinical issues (pp. 202-214). New York, New York: Springer.

Owens, C. (2005). Moved to tears: Technical considerations and dilemmas encountered in working with a 13-year-old boy with acquired quadriplegia. Journal of Child Psychotherapy, 31, 284-302. doi:10.1080/00754170500370753

Pope, K. S., Tabachnick, B. G., \& Keith-Spiegel, P. (1987). Ethics of practice: The beliefs and behaviors of psychologists as therapists. American Psychologist, 42, 993-1006. doi:10.1037/0003-066X.42.11.993

Rhue, J. W. (2001). Death, bereavement, and the therapist. In S. Kahn \& E. Fromm (Eds.), Changes in the therapist (pp. 117-131). Mahwah, NJ: Lawrence Erlbaum.

Ruesch, J., \& Rees, W. (1959). Non-verbal communication. Los Angeles: University of California Press.

Searles, H. F. (1955). The informational value of the supervisor's emotional experiences. Psychiatry: Journal for the Study of Interpersonal Processes, 18, 135-146. 
Sung, A. D., Collins, M. E., Smith, A. K. Sanders, A. M., Quinn, M. A., Block, S. D., \& Arnold, R. M. (2009). Crying: Experiences and attitudes of third-year medical students and interns. Teaching and Learning in Medicine, 21, 180-187. doi:10.1080/10401330903014111

Tracey, T. G., Bludworth, J., \& Glidden-Tracey, C. E. (2011). Are there parallel processes in psychotherapy supervision? An empirical examination. Psychotherapy, 49, 330-343. doi:10.1037/a0026246

Trezza, G. R., Hastrup, J. L., \& Kim, S. E. (1988) Clinicians' attitudes and beliefs about crying behavior. Fifty-ninth Annual Meeting of the Eastern Psychological Association, Buffalo, NY.

van Hemert, D. A., van de Vijver, F. R., \& Vingerhoets, A. M. (2011). Culture and crying: Prevalences and gender differences. Cross-Cultural Research, 45(4), 399-431. doi:10.1177/1069397111404519

Vingerhoets, A. J. J. M., Boelhouwer, A. J. W., Van Tilburg, M. A. L., \& Van Heck, G. L. (2001). The situational and emotional context of crying. In A. J. J. M. Vingerhoets \& R. R. Cornelius (Eds.), Adult crying: A biopsychosocial approach (pp. 71-89). Reading, England: Harwood.

Vingerhoets, A. J. J. M., \& Cornelius, R. R. (2001). Adult crying: A biopsychosocial approach. Hove, UK: Brunner-Routledge.

Vingerhoets, A. J., Cornelius, R. R., Van Heck, G. L., \& Becht, M. C. (2000). Adult crying: A model and review of the literature. Review of General Psychology, 4, 354 -377. doi:10.1037/1089-2680.4.4.354

Waldman, J. L. (1995). Breakthrough or breakdown: When the psychotherapist cried 
during the therapy session (Doctoral dissertation). Retrieved from Dissertation and Theses database. (UMI No. 9536358)

Yalom, I. D. (2002). The gift of therapy: An open letter to a new generation of therapists and their patients. New York, New York: HarperCollins. 